\title{
Article \\ Shifts in Ecological Dominance between Two Lepidopteran Species in Refuge Areas of Bt Cotton
}

\author{
José Bruno Malaquias ${ }^{1, *(D)}$, Danilo Renato Santiago Santana ${ }^{2}$, Paulo Eduardo Degrande ${ }^{2}$, Claudia Pio Ferreira ${ }^{1}$, \\ Elmo Pontes de Melo ${ }^{3}$, Wesley Augusto Conde Godoy ${ }^{4}$, Jéssica Karina da Silva Pachú ${ }^{4}$, \\ Francisco de Sousa Ramalho ${ }^{5}$, Celso Omoto ${ }^{4}$, Alexandre Igor de Azevedo Pereira ${ }^{6}$ and \\ Renato Anastacio Guazina ${ }^{2}$
}

check for updates

Citation: Malaquias, J.B.; Santana, D.R.S.; Degrande, P.E.; Ferreira, C.P.; de Melo, E.P.; Godoy, W.A.C.; Pachú, J.K.d.S.; de Sousa Ramalho, F.; Omoto, C.; de Azevedo Pereira, A.I.; et al. Shifts in Ecological Dominance between Two Lepidopteran Species in Refuge Areas of Bt Cotton. Insects 2021, 12, 157. https://doi.org/ $10.3390 /$ insects 12020157

Academic Editor: Peter Armbruster

Received: 22 December 2020

Accepted: 10 February 2021

Published: 12 February 2021

Publisher's Note: MDPI stays neutral with regard to jurisdictional claims in published maps and institutional affiliations.

Copyright: (c) 2021 by the authors. Licensee MDPI, Basel, Switzerland. This article is an open access article distributed under the terms and conditions of the Creative Commons Attribution (CC BY) license (https:/ / creativecommons.org/licenses/by/ $4.0 /)$.
1 Department of Biostatistics, Institute of Biosciences-IBB, São Paulo State University (UNESP), Botucatu 18618-693, Brazil; claudia.pio@unesp.br

2 Department of Entomology, Federal University of Grande Dourados (UFGD), Dourados 79825-070, Brazil; danilosantana1987@hotmail.com (D.R.S.S.); PauloDegrande@ufgd.edu.br (P.E.D.); renatoaguazina@hotmail.com (R.A.G.)

3 Federal Institute of Mato Grosso do Sul, Ponta Porã 79909-000, Brazil; elmo.melo@ifms.edu.br

4 Department of Entomology and Acarology, Luiz de Queiroz College of Agriculture (ESALQ), Piracicaba 13418-900, Brazil; wacgodoy@usp.br (W.A.C.G.); jessikapachu@gmail.com (J.K.d.S.P.); celso.omoto@usp.br (C.O.)

5 Biological Control Unit, Embrapa Cotton, Campina Grande 58428-095, Brazil; ramalhohvv@gmail.com

6 Goiano Federal Institute, Urutaí 75790-000, Brazil; alexandre.pereira@ifgoiano.edu.br

* Correspondence: malaquias.josebruno@gmail.com

Simple Summary: Understanding the reasons that substantiate competitive strategies as a result of selective pressure and their consequences for the dynamics of competitors under specific conditions is one of the key issues in Game Theory. Here, we discuss how the adoption of insecticide control in refuge areas and the occurrence of Spodoptera frugiperda and Helicoverpa armigera resistance to insecticides could impact the large-scale production of individuals in refuge areas of Bt cotton in the context of competition dynamics. In view of our results, we emphasize the necessity of carefully managing refuge areas of Bt cotton in agroecosystems that have both $S$. frugiperda and H. armigera.

Abstract: Competition behavior involving agricultural pest species has long been viewed as a powerful selective force that drives ecological and phenotypic diversity. In this context, a Game Theory-based approach may be useful to describe the decision-making dilemma of a competitor with impacts to guarantee its superiority in terms of ecological dominance or sharing of the food resource with its competitor. In an attempt to elucidate the consequences of competitive dynamics for the ecological dominance of these species in refuge areas of Bt cotton, we conducted a study that was divided into two parts. The first study consisted of an evaluation of interactions involving Spodoptera frugiperda (JE Smith, 1797) and Helicoverpa armigera (Hübner, 1808) on non-Bt cotton plants in a field trial. In the second study, we explored the data matrix collected in the field to parameterize a model of Cellular Automata (CA) with update rules inspired by Game Theory. Computer simulations were analyzed in hypothetical scenarios involving the application (or not) of insecticides in the refuge areas in combination with the resistance factor of one or both pest species to the insecticides used in the refuge areas. $H$. armigera had superior competitive performance in relation to $S$. frugiperda only at high densities. According to the density-mediated shift in dominance of the species, the resistance of $S$. frugiperda to insecticides is seen as a risk factor for the production of susceptible individuals of $H$. armigera on a large scale in the refuge areas. Additionally, $S$. frugiperda insecticide resistance may potentially impact the resistance evolution of the $H$. armigera population to Bt cotton. Thus, ecological dominance could diverge by the presence of a resistance allele to insecticides with interspecific competition perhaps subordinate to evolutionary processes.

Keywords: resistance management; competition; spatial model 


\section{Introduction}

Competition between species has shaped broad-scale patterns of the phenotypic diversity of agricultural pests, and this can be impacted in several ways. One of them is density dependence, which is one of the main factors associated with competition for food resources in a wide variety of insect species, as it directly influences the individual or population fitness of these organisms. In general, density dependence may be regulated by ecological population mechanisms, which lead to shifts in the population structure of species [1]. The nature of these intra- and interspecific interactions can vary according to the evolutionary context and environmental conditions [2]. Experimental and theoretical studies have generally been limited by the lack of methodological approaches to analyze species interactions [3].

The strategic situation in which competitors make different decisions according to the condition of selection pressure may be analyzed with Game Theory [4]. In general, Game Theory formalism is based on competitor behavioral decision making on an individual basis; however, the payoff for each player will depend on the decision made by all competitors who are interacting [5]. The key issue of Game Theory is the understanding of the reasons for decisions given by certain scenarios and their consequences for population fitness under specific conditions [6]. The prisoner's dilemma is a standard example of Game Theory, which shows why two individuals may not cooperate [4,7]. Game Theory can jointly consider the ecological and evolutionary dynamics of competitors [8]. Despite the frequent use of Game Theory concepts in studies involving cooperative behavior, little attention has been given to the development of models capable of explaining the competition dynamics of pest species in neotropical agroecosystems [9].

Bacillus thuringiensis $\delta$-endotoxins (Bt toxins) have been widely used in transgenic cotton due to their toxicity and specificity against important lepidopteran pests from Brazilian cotton agroecosystems, such as Spodoptera frugiperda (JE Smith 1797) and Helicoverpa armigera (Hübner, 1808) (Lepidoptera: Noctuidae). To delay the evolution of resistance to Bt crops and insecticides, the high dose/refuge strategy has been designed to prevent resistance evolution in insect populations against $\mathrm{Bt}$ toxins. This strategy could be effective if the following assumptions are met: resistance alleles to a Bt protein are rare; a Bt protein is consistently produced by a plant at a highly toxic concentration, with resistance alleles that are functionally recessive; and cultivation of refuge areas with non-Bt plants [10]. Refuges of non-Bt crops can be a source of Bt- or insecticide-susceptible individuals that contribute to delaying resistance [11,12]. Ideally, these refuges are planted near Bt crop fields or fields where critical insecticides are used to allow Bt-resistant insects to mate with susceptible insects produced in refuges [13].

A high-dose Bt plant expresses a high concentration of toxin to ensure that at least $95 \%$ of the heterozygous individuals carrying one copy of a resistance allele may be controlled [14]. High mortality of the heterozygous of S. frugiperda on Bt cotton varieties Wi-deStrike ${ }^{\circledR}$ and TwinLink ${ }^{\circledR}$ has been found in Brazil [15]. However, the intensive planting systems in Brazil have promoted the emergence of a high frequency of individuals resistant to synthetic insecticides and Bt crops. For example, S. frugiperda rapidly evolved resistance to the $\mathrm{Bt}$ toxin $\mathrm{Cry} 1 \mathrm{~F}$ produced by $\mathrm{Bt}$ cotton and maize [16], Cry1 $\mathrm{Ab}$ in cotton, maize and soybean [17], and Cry1A.105 in maize [18]. High susceptibility to Cry1Ac of Helicoverpa armigera has also been documented in Brazil [10]. However, due to H. armigera having low susceptibility to Vip3Aa20, Leite et al. [19] highlight that it is extremely important to monitor the susceptibility of $H$. armigera populations, when crops such as cotton are expressing Vip3Aa20 protein. Although Bt crops can reduce the insecticide sprays to control lepidopteran pests [20,21], on average, in Brazil, it is still necessary to spray insecticides 7 to 9 times in cotton [22]. As a result, S. frugiperda and H. armigera, in some regions in Brazil, have rapidly evolved resistance to new insecticides, such as diamides [22,23].

Spodoptera frugiperda and H. armigera are cannibalistic in their larval stage [24]. At the field level, these pests can infest the plant simultaneously during the season and feed on the same cotton structures, such as squares, flower, bolls, and blooms. Thus, they may compete 
for food resources, exhibiting different behavioral strategies inherent to each species, with intraguild competition involving these two species [25] as a mechanism to guarantee the survival and/or ecological dominance of the one species in the agroecosystem.

The influence of cannibalism and competition between immature S. frugiperda and $H$. armigera in situations of density dependence has not been clearly demonstrated. A question of interest to both researchers and cotton farmers in countries with the simultaneous occurrence of $S$. frugiperda and $H$. armigera species would be: What are the competition dynamics of these pests in cotton plants that do not express Bacillus thuringiensis (Bt), and which are used as refuge areas for Bt cotton? Based on the assumption that refuge areas are essential for the management of insect resistance to Bt technology, and as they aim at the large-scale production of individuals susceptible to Bt plants [26], a second question would be: How do the competition dynamics of these lepidopterans impact the production of individuals in those refuge areas?

To answer the previous two questions, we have structured this research into two parts. The first part aimed at understanding the intra- and interspecific interaction between $H$. armigera and S. frugiperda in non-Bt cotton plants, through biological experiments conducted in the field, whose results were used to parameterize a computer model based on cellular automata. Cellular automata (CA) constitute simple mathematical models, in which space and time are discrete [27]. A regular lattice with a CA in each cell (site or patch) is set following a series of well-defined rules based on a pre-specified neighborhood of the cellular automata interacting in time [28]. Results from the model constituted the second part of our research. The structure of a spatial game model was used in cellular automata described in a formal way and exploring a finite set of competitors. In this case, the larvae are the competitors (players); the interactions involving the competitors are given by the competition strategies in each scenario analyzed and according to the payoff matrix corresponding to the survival rate of the larvae obtained from our intra- and interspecific competition experiments involving H. armigera and S. frugiperda. Therefore, the competition strategies that are being addressed in our cellular automata are those related to competition among individuals of the same species, and between those of different species.

Taking into account that the evaluation of the consequences of competitive behavior for the population dynamics of $S$. frugiperda and $\mathrm{H}$. armigera in refuge areas for Bt cotton technology is of great economic relevance, we focused in our field experiments on the density dependence interactions occurring between competing larvae of S. frugiperda and $H$. armigera that could exist within the same non-Bt cotton plant. We also explore, with computer simulations, hypothetical scenarios that were chosen based on possible cases found in Bt cotton agroecosystems, for example, the use of insecticide control with synthetic insecticides in refuge areas [29]. Given the high selection pressure in tropical countries and the impact of the density dependence in resistance evolution, cases of resistance of one or both species to the insecticides used in the refuge areas are expected.

Simulations were carried out in order to explain, from an ecological point of view, the relative dominance of the pests in the analyzed agroecosystems and to contribute to the design of a sustainable management of $S$. frugiperda and $H$. armigera in refuge areas, aiming at the maximum production of Bt-susceptible adults on a large scale, making it possible to delay the resistance evolution of these pests to Bt cotton. Thus, in our simulations, we analyzed the population dynamics occurring with the occupation of the different density state species in the cells (patches) of the cellular automata and, after that, we calculated the relative dominance of each species by each area in five scenarios, as follows: (i) absence of insecticides; (ii) adoption of insecticides without cases of resistance; (iii) adoption of insecticides with population resistance of $S$. frugiperda; (iv) adoption of insecticides with population resistance of $H$. armigera; (v) adoption of insecticides with population resistance of $S$. frugiperda and H. armigera. 


\section{Materials and Methods}

\subsection{Intra- and Interspecific Competition in the Field}

Location and Experiment Characterization: The experiment was conducted in an experimental area located at the Federal University of Grande Dourados (UFGD in Dourados, Mato Grosso do Sul, MS), in the 2017/2018 cotton season, between November 2017 (soil preparation and tillage) and June 2018 (end of the cotton cycle, 154 days after seedlings emergence).

Insects: The insects were provided by the Pragas.com company. Both species were reared on artificial diets [30], in a conditioned room under temperature of $25 \pm 2{ }^{\circ} \mathrm{C}$, relative humidity of $70 \pm 5 \%$, and $12 \mathrm{~h}$ of photophase, for more than 5 generations in the absence of selection pressure by insecticides and/or Bt proteins for intra- and interspecific competition studies in the field.

The studies with the isolated species and in combinations were carried out in the field with confinement of the insects in the larval stage, at the R1 reproductive stage of the cotton plants.

Non-Bt cotton plants (FiberMax FM 944GL ${ }^{\circledR}$ BASF) were grown in the field with soil classified, according to Embrapa [31], as Dystrophic Red Latosol. The cotton seeds were sewn by hand in December 2017 with a spacing of $0.90 \mathrm{~m}$ in rows and density of eight seeds $/ \mathrm{m}$. Fertilizers were applied according to the recommended management for the crop. Weed control was manual and the experimental crop was irrigated when necessary.

The plot consisted of four rows, each row with a length of $4 \mathrm{~m}$. As a useful plot, the central row (2nd or 3rd row) was taken, with $1.0 \mathrm{~m}$ at each end border, totaling $7.20 \mathrm{~m}^{2}$ of usable area where we selected one single plant (the sample unit). Thus, the larvae of each species were confined in an isolated plant.

The infestations were carried out with $H$. armigera and S. frugiperda neonates in a single plant of cotton, with two trials arranged independently, as follows:

Experiment 1 -Intraspecific competition with $S$. frugiperda and $H$. armigera species kept isolated, with densities of: 5, 10, 15, and 20 larvae per plant.

Experiment 2-Intra- and interspecific competition involving S. frugiperda and H. armigera on the same plant, with densities of 5, 10, 15, and 20 larvae of each species per plant.

The neonates were placed with a paintbrush in the cotton squares. Cages were installed on the cotton plants with the following dimensions: $0.70 \times 0.70 \mathrm{~m}$ wide (at the base) and $1.40 \mathrm{~m}$ high, covered with voile Bell- $34^{\circledR}$. Thus, the larvae could not escape and we could avoid natural (external) infestation. We used the Randomized Block Design (RBD) in a $4 \times 2$ factorial treatment arrangement, with four densities (factor one), two species (factor two), and four blocks = four plants/treatment in total. The evaluations were performed 10 days after the infestation, recording the total number of surviving insects.

Data analysis: Two generalized linear models, one model for each experiment, with binomial distribution were fitted to the survival data of $S$. frugiperda and $H$. armigera larvae. The goodness of fit of a statistical model was confirmed using a simulated half-normal plot using the R package hnp [32].

\subsection{Computer Simulation}

\subsubsection{Description of the Proposed Model}

In the model parameterization, the results of the intra- and interspecific competition experiments involving $H$. armigera and $S$. frugiperda were used. We used two density conditions, "high" and "low". A density of 5 larvae of each species per cotton plant was considered a "low density" condition, while the "high density" condition was 20 larvae of each insect species per cotton plant. The explored data related to larval survival rate are expressed in the results, and explained in more detail throughout the description of the cellular automata rules.

A two dimension $(1000 \times 1000$ cells) cellular automata model was used in the simulations. After species interaction, each cell can assume one of the three states: "presence of S. frugiperda" (species 1), "presence of H. armigera" (species 2), or "absence of any of the 
species". Parallel update with periodic boundary conditions and the Moore neighborhood with radius one were used.

Each cell in the automata represents a cotton plant. Each time step, $t$, corresponds to a generation of insects. The update rules were:

(a) Occupied Site: A cell occupied by species one or two may become empty due to two independent conditions:

Condition I. With $\mu$ probability (Natural Mortality (NM) parameter described in the sensitivity analysis), the occupied site becomes empty, due to the effects of natural mortality factors and/or dispersal (displacement) to other areas.

Condition II. If the situation described in item 1 does not occur, this site may be empty with probability $\theta$, due to intra- and/or interspecific competition which was calculated as follows: First, the number of occupied sites in the Moore neighborhood (eight closest neighbors) was calculated. If this number is greater than or equal to $T$ (threshold previously defined), which represents a density state, then Matrix H (High Density Matrix) was selected (Figure 1); otherwise, data from Matrix L (Low Density Matrix) (Figure 1) were used. Subsequently, the encounter probability between two competing species was calculated, which also depended on the number of sites occupied by each species in the Moore neighborhood. If the species were on the same plant during the larval stage, the probability for the survival of that phase was given by the intra- and interspecific interactions (secondary diagonals of Matrices $\mathbf{H}$ or $\mathbf{L}$ ) (Figure 1). Otherwise, the survival probability was given only by intraspecific interactions (principal diagonals of Matrices $\mathbf{H}$ or $\mathbf{L}$ ) (Figure 1). The parameter, $\theta$, previously defined, was one minus the survival probability.

MATRIX H (High density)

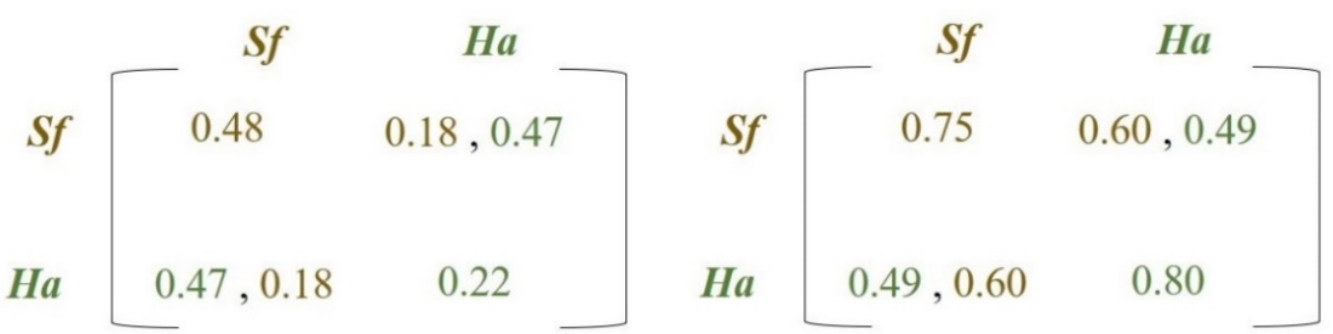

Figure 1. Payoff matrices containing the survival probabilities of Helicoverpa armigera (Ha) (green values) and Spodoptera frugiperda (Sf) (brown values). The matrices represent the payoffs given the inter + intraspecific interactions (principal diagonal) or only interspecific interactions (secondary diagonal) for states with high population densities (MATRIX H (High density)) or low population densities (MATRIX L (Low density)). These results were obtained in the biological experiments and they are expressed in Figure 2A-C (Section 3). (For a color version of this figure, the reader is referred to the web version of this article.).

Condition III. If the conditions I and II were not met, then the site was still occupied. An example summarizing the rules mentioned above is provided below:

If the individuals' frequency in the local neighborhood is greater than 0.50 (arbitrary density state-MATRIX H, Figure 1) and the probability of encounter on the same site between these species is not met, the probabilities of larval survival of $S$. frugiperda and $H$. armigera are 0.48 and 0.22 (principal diagonal of MATRIX H-Figure 1), respectively. In the case of encounter between these two species, the larval survival probability of $S$. frugiperda is 0.18, while that of H. armigera is 0.47 (secondary diagonal of MATRIX H-Figure 1). 

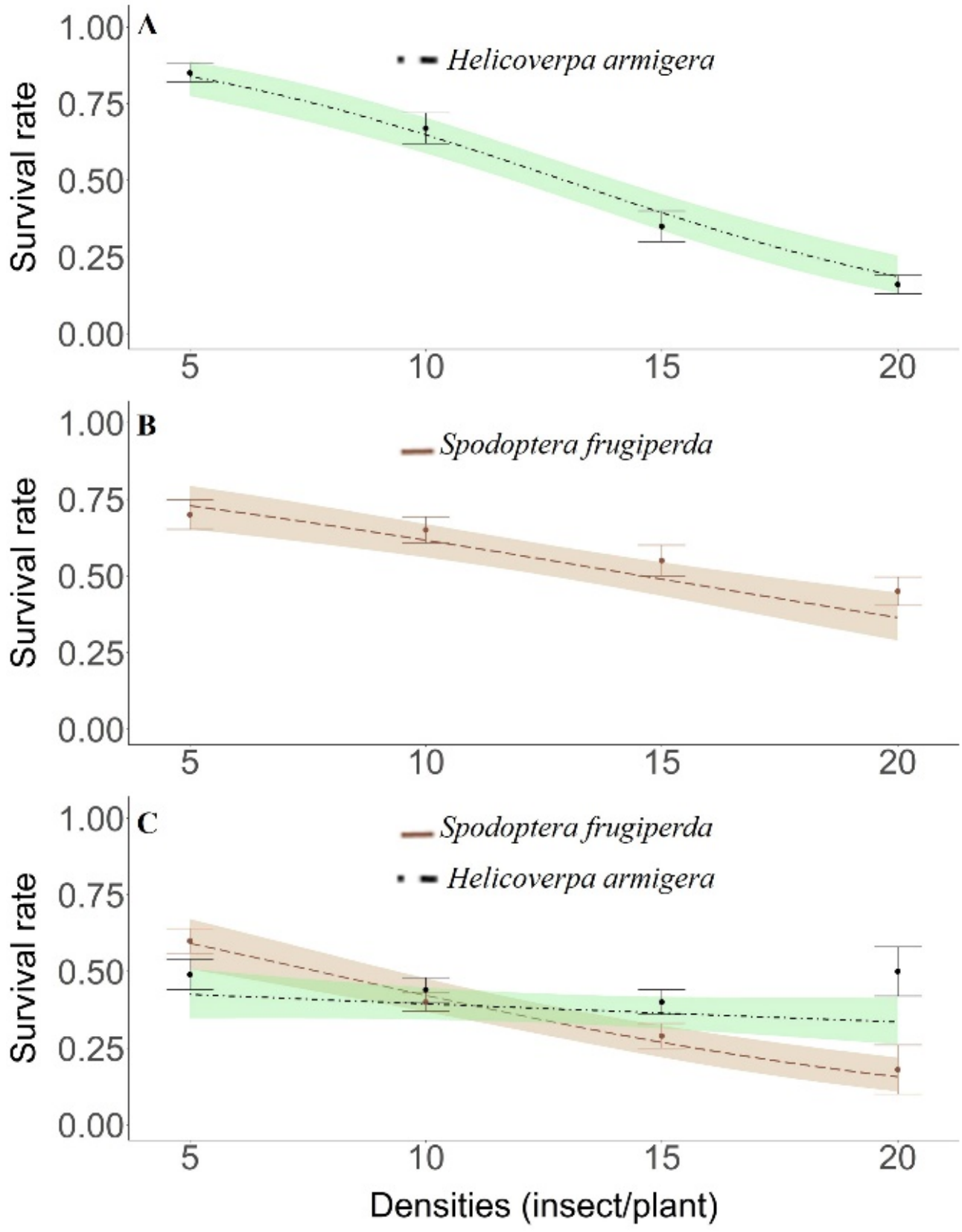

Figure 2. In-field survival rate (mean $\pm \mathrm{SE}$ ) of Spodoptera frugiperda and Helicoverpa armigera larvae isolated (intraspecific competition only) and combined (intra- and interspecific competition). Dashed curve corresponds to the observed data, while the colored areas are the confidence regions (95\% CR) predicted by the generalized linear model with binomial distribution. (For a color version of this figure, the reader is referred to the web version of this article.). (A) Only H. armigera; (B) Only $S$. frugiperda; (C) S. Frugiperda + H. armigera.

(b) Empty Site: An empty site may become occupied with probability $W$, due to the insect oviposition in the Moore neighborhood. The probability $W$ was given by the relative fitness $\left(f_{1}\right.$ and $\left.f_{2}\right)$.

We estimated the relative fitness based on the reproductive success of each insect species on reaching the adult stage. To calculate reproductive success, the number of insects of each species in a Moore neighborhood was multiplied by their respective reproductive capacity $\left(R_{0}\right)$. 
The reproductive capacity considered in the model was based on the number of eggs and neonate hatch rate, according to biological data on H. armigera and S. frugiperda collected in cotton by Gomes [33] and Barros et al. [34], respectively.

The probability of species one (S. frugiperda) ovipositing is given by $f_{1}$. If species one does not oviposit, then the probability of oviposition of species two (H. armigera), given by $f_{2}$, is tested. If none of the species oviposit, then the site remains empty.

Description of the Scenarios Used in the Simulations: The relative dominance as a function of the time of each species by area and which involves the proportion of individuals of each species in relation to the total was calculated in five scenarios, as follows:
A. Non-adoption of insecticides.
B. Adoption of insecticides without cases of resistance.
C. Adoption of insecticides with population resistance of $S$. frugiperda to the used insecticide.
D. Adoption of insecticides with population resistance of $H$. armigera to the used insecti- cide.
E. Adoption of insecticides with population resistance of S. frugiperda and H. armigera to the used insecticide.
The insecticide was sprayed only when one of the species reached the arbitrary control level (parameter CL-see Table 1) of $20 \%$. We checked in each time step if the number of cells had reached the proportion of 0.20 for at least one of the species in relation to the total number of cells.

Table 1. Description values and parameters used in the simulations (S) of the model and in the sensitivity analysis (SA).

\begin{tabular}{|c|c|c|c|}
\hline Parameter & Description & Value-S $^{1}$ (Value-AS) $^{2}$ & Reference \\
\hline$A E$ & Adult emergency & $0.86(0.65-1.00)$ & \\
\hline$\mho$ & Encounter rate between species 1 and 2 & * & - \\
\hline$T$ & Threshold for defining the state (high or low) of density & $0.50(* * *)$ & ** \\
\hline$C L$ & Threshold for decision making for insecticide control & $0.2000(0.15-0.25)$ & - \\
\hline $\mathrm{R}_{0} \mathrm{Ha}$ & $\begin{array}{c}\text { Reproductive capacity (neonates/female) of } \\
\text { Helicoverpa armigera }\end{array}$ & $725.06(543.80-965.33)$ & Gomes et al. [33] \\
\hline$R_{o} S f$ & $\begin{array}{l}\text { Reproductive capacity (neonates/female) of } \\
\text { Spodoptera frugiperda }\end{array}$ & $400.00(300.00-500.00)$ & Barros et al. [34] \\
\hline$W_{\mathrm{Ha}}$ & Relative fitness of $H$. armigera & * & - \\
\hline$N M$ & Probability associated with mortality factors $\#$ & $0.25(0.19-0.31)$ & Varella et al. [35] \\
\hline$W_{S f}$ & Relative fitness of $S$. frugiperda & * & - \\
\hline$I F$ & $\begin{array}{l}\text { Initial number (absolute frequency) of H. armigera and } \\
\text { S. frugiperda }\end{array}$ & $500(375-625)$ & \\
\hline$\alpha_{11}$ & $\begin{array}{l}\text { Survival of } S \text {. frugiperda in intraspecific competition at } \\
\text { low densities }\end{array}$ & $0.63(0.47-0.79)$ & $* * * *$ \\
\hline$\alpha_{12}$ & $\begin{array}{l}\text { Survival of } S \text {. frugiperda in intra- and interspecific competition } \\
\text { at low densities }\end{array}$ & $0.58(0.44-0.73)$ & $* * * *$ \\
\hline$\alpha_{21}$ & $\begin{array}{l}\text { Survival of } H \text {. armigera in intraspecific competition at } \\
\text { low densities }\end{array}$ & $0.46(0.35-0.58)$ & $* * * *$ \\
\hline$\alpha_{22}$ & $\begin{array}{l}\text { Survival of } H \text {. armigera in intra- and interspecific competition } \\
\text { at low densities }\end{array}$ & $0.90(0.68-1.00)$ & $* * * *$ \\
\hline$\beta_{11}$ & $\begin{array}{c}\text { Survival of S. frugiperda in intraspecific competition at } \\
\text { high densities }\end{array}$ & $0.31(0.23-0.39)$ & $* * * *$ \\
\hline$\beta_{12}$ & $\begin{array}{l}\text { Survival of } S \text {. frugiperda in intra- and interspecific competition } \\
\text { at high densities }\end{array}$ & $0.11(0.08-0.14)$ & $* * * *$ \\
\hline$\beta_{21}$ & $\begin{array}{c}\text { Survival of } H \text {. armigera in intraspecific competition at } \\
\text { high densities }\end{array}$ & $0.38(0.29-0.48)$ & $* * * *$ \\
\hline$\beta_{22}$ & $\begin{array}{c}\text { Survival of } H \text {. armigera in intra- and interspecific competition } \\
\text { at high densities }\end{array}$ & $0.16(0.12-0.18)$ & $* * * *$ \\
\hline
\end{tabular}

\# Mortality factors by natural enemies and/or in case of dispersal. ${ }^{1}$ Value of the parameter used in the simulations. ${ }^{2}$ Values of the parameters. * Random, according to the density of individuals of species one and two in the Moore neighborhood of radius 1 (eight closest neighbors). ${ }^{* *}$ Arbitrary value. ${ }^{* *}$ Parameter not used in the sensitivity analysis. ${ }^{* * * *}$ Data collected in biological experiments. 
The Cellular Automata (CA) model was parametrized with the data provided using a logistic regression model (Figure 2) with Bayesian inference adjusted to the experimental data collected in the field experiments. The rules of the CA model followed prisoner's dilemma (Game Theory). The initial number (absolute frequency) of individuals was 500 individuals of each species or a relative dominance of 0.50 .

The mortality probability from the use of insecticide of 0.99 was considered for larvae surviving the effects of natural mortality or displacement factors (dispersal to other agroecosystems). The use of insecticide did not alter any other rules of the automata. For the scenarios of resistance occurrence, we assumed that the population was in Hardy-Weinberg equilibrium, and that the initial frequency of insecticide-resistant individuals adopted in the simulations was 0.0625 .

A description is presented in Table 1 of all the parameters, as well as their adopted values in the simulations and the range explored in the sensitivity analysis.

\subsubsection{Parameter Sensitivity Analysis}

We measured the impacts of fluctuations in parameters of our model on the outputs. The sensitivity analysis is based on a unique Principal Component Analysis (PCA). The sensitivity indices were estimated based on the weighted participation of each parameter in the main components, thus calculating the generalized sensitivity index, according to the method described by Lamboni et al. [36] in the R package multisensi [37]. The parameter values for sensitivity analysis were obtained through uniform distribution (Table 1).

The ranges of uniform distribution for each parameter were given by a rate of change of $25 \%$ of the original value for each parameter. A detailed description of the parameter values and the range used in the sensitivity analysis is shown in Table 1.

\section{Results}

\subsection{Intra- and Interspecific Competition in the Field}

A linear decline in the survival rate was found for both species, H. armigera and $S$. frugiperda, kept in non-Bt cotton plants either in isolation (intraspecific competition) or combined (interspecific competition) in the evaluated density range (Figure $2 \mathrm{a}-\mathrm{c}$ ). Independently of $S$. frugiperda larvae density, kept in isolation, there was competition between the larvae of this species, with the survival rate ranging near to 0.75 and 0.50 in the densities of 5 and 20 larvae per plant, respectively (Figure 2b). H. armigera had maximum and minimum survival rates of 0.80 and 0.22 at densities of 5 and 20 larvae per plant, respectively, in the same isolated confinement bioassay (Figure 2a).

In the intra- and interspecific interaction assay involving $S$. frugiperda versus $H$. armigera larvae, the species with the highest survival in the lowest and intermediate densities was S. frugiperda. On the other hand, at a density of 20 larvae of each species, the greater predominance was of $H$. armigera larvae (survival rate $>0.45 \%$ ) in relation to $S$. frugiperda (survival rate <0.20) (Figure 2c).

\subsection{Computer Simulation}

The simulations revealed that, over the course of 80 generations (Figure 3a-d), $S$. frugiperda was the dominant species in all scenarios with exception only in the scenario of adopting insecticide control and resistance of only $H$. armigera to the insecticide, where there was dominance of $H$. armigera (Figure $3 \mathrm{~d}$ ). The greatest negative impacts on the population dynamics of $H$. armigera were with the use of insecticide control and with the occurrence of $S$. frugiperda resistance to the insecticide, providing the formation of small islands of its competitor (Figure 3c). Similarly, despite the resistance of both species to the insecticide used in the refuge areas (Figure 3e), the patch competition between larvae ne-gatively impacted the $H$. armigera population.

In the analysis on the time evolution of the patch occupation by the competitors, the lowest population impacts were observed for $H$. armigera when there was no adoption 
of insecticide control in the refuge areas, among the scenarios with predominance of $S$. frugiperda (Figure 4a).
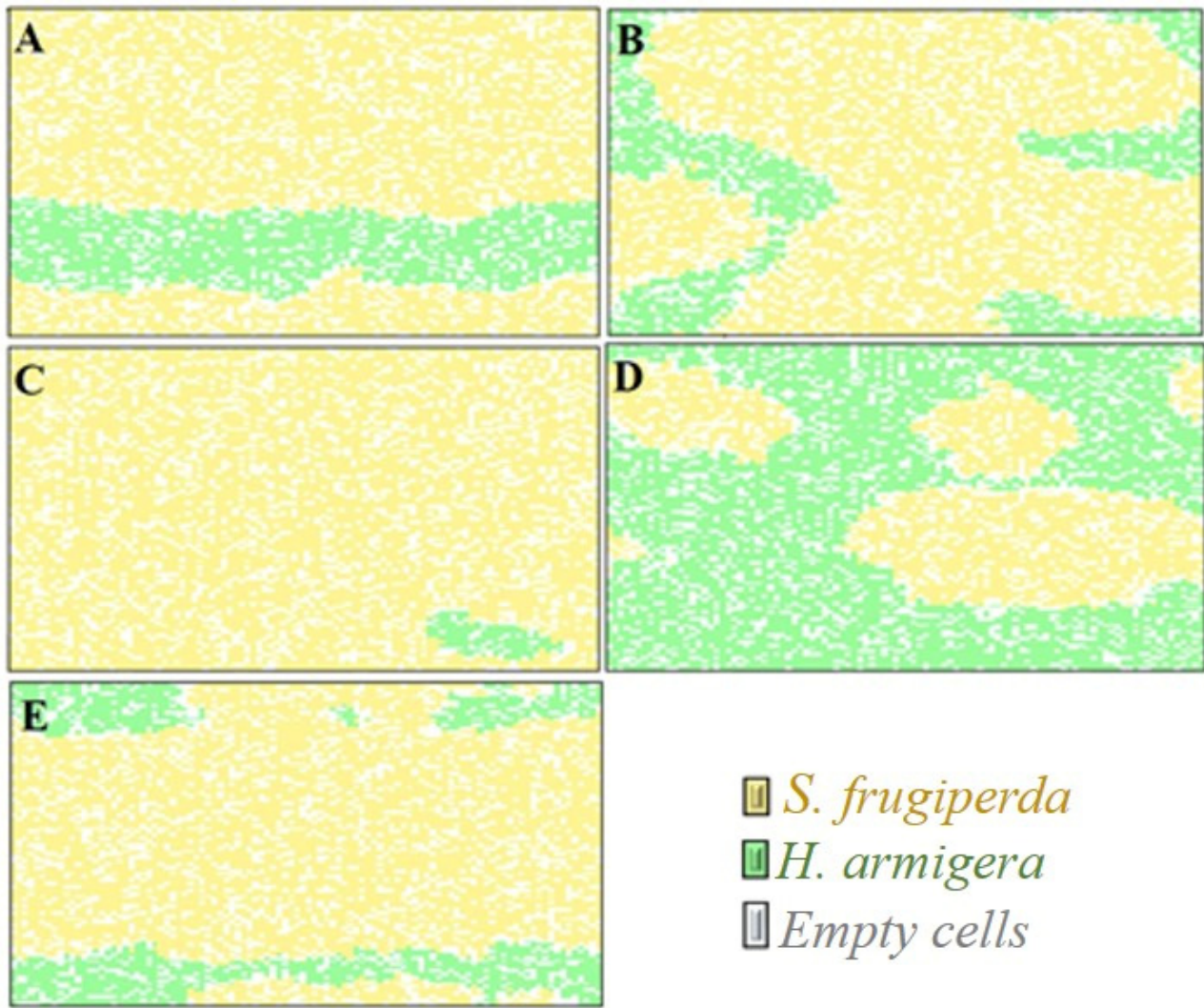

Figure 3. Visual representation of the occupation of patches by S. frugiperda and H. armigera after 80 time steps in the following conditions: (A): absence of insecticide control. (B): insecticide control and absence of cases of insecticide resistance. (C): insecticide control and resistance of $S$. frugiperda to the insecticide. (D): insecticide control and resistance of $H$. armigera to the insecticide. (E): insecticide control and resistance of $S$. frugiperda and $H$. armigera to the insecticide. (For a color version of this figure, the reader is referred to the web version of this article.)

In the absence of insecticide control, the curves of competing species have the same intercept; in other words, the same origin of ecological dominance evolution (Figure 4a).

In the scenario of insecticide control with no cases of resistance for both species, the results from our modelling revealed that despite the small difference, the curves of competing species do not have a common intercept (Figure $4 \mathrm{~b}$ ). In addition, the ecological dominance was increasing and significantly higher in S. frugiperda in relation to H. armigera, since there was no overlapping of the curves at any time (Figure $4 \mathrm{~b}$ ).

In the adoption of insecticide control and the occurrence of resistance for S. frugiperda, the simulations revealed a high dominance of this species in relation to H. armigera over the generations. Although there was no risk of extinction of $\mathrm{H}$. armigera, its relative do-minance was estimated to be less than $10 \%$ after 70 steps of time (Figure $4 \mathrm{c}$ ).

The incorporation of the resistance of $H$. armigera and the absence of this genetic trait in S. frugiperda resulted in the ecological dominance of the first species. Nevertheless, the predicted curves of ecological dominance of competing species over time were contrasting; therefore, in S. frugiperda, the response was increasing, while in H. armigera, it was decreasing (Figure $4 \mathrm{~d}$ ).

In the scenario with the use of insecticide control and resistance of both species in the refuge areas, we obtained a greater dominance of $H$. armigera in relation to $S$. frugiperda in the interval that precedes 18 initial time steps (generations). After this, there was an 
overlap of the curves, followed by a shift in the ecological dominance; therefore, after this period, the dominant species was S. frugiperda (Figure 4e).
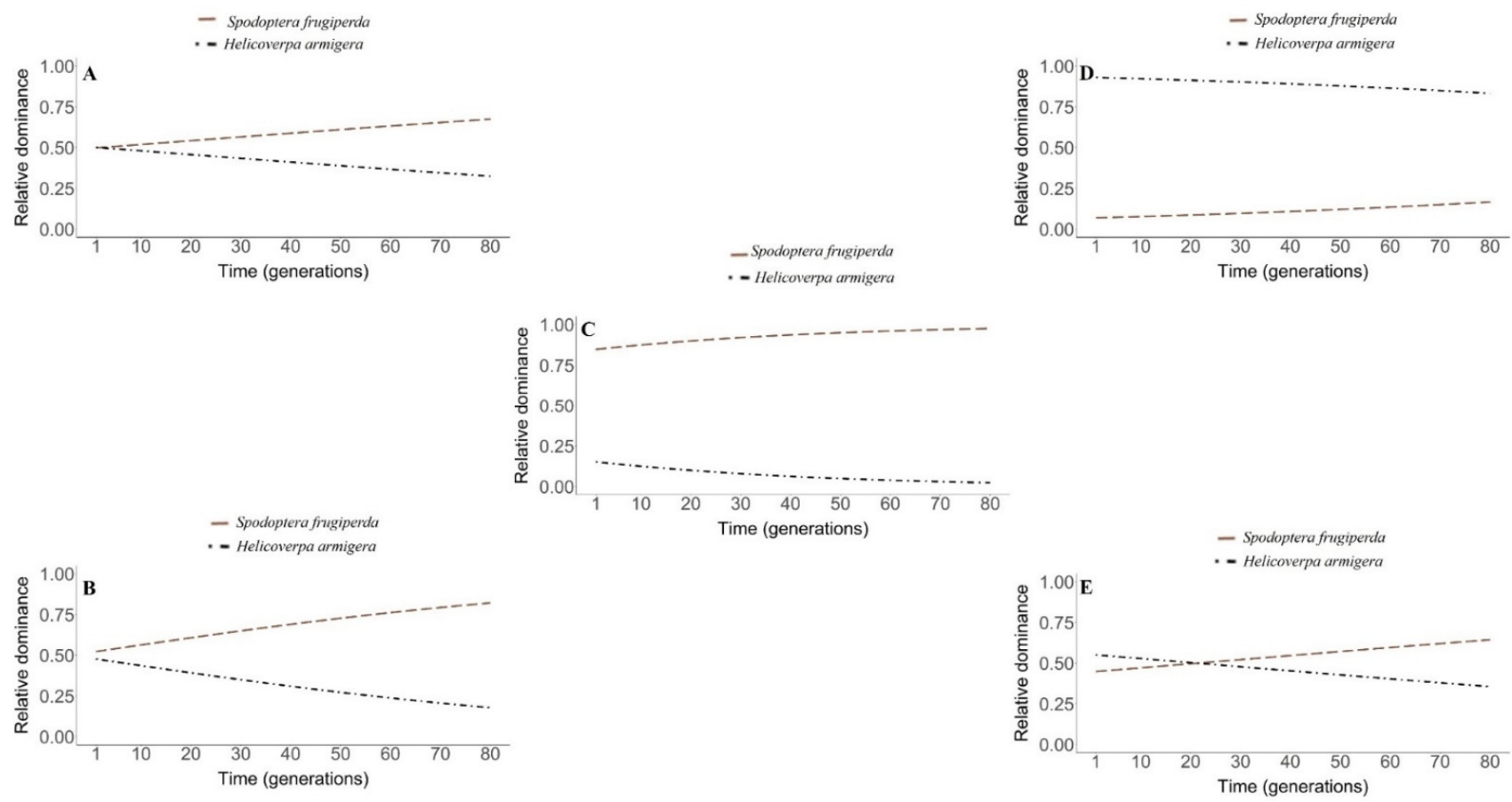

Figure 4. Dynamics of temporal evolution of the ecological dominance of $S$. frugiperda (light salmon long dashed line) and H. armigera (black dotted line) in the following conditions: (A): absence of insecticide control. (B): insecticide control and absence of cases of insecticide resistance. (C): insecticide control and resistance of $S$. frugiperda to the insecticide. (D): insecticide control and resistance of $H$. armigera to the insecticide. (E): insecticide control and resistance of S. frugiperda and H. armigera to the insecticide. (For a color version of this figure, the reader is referred to the web version of this article.)

\subsection{Sensitivity Analysis}

Based on the generalized sensitivity index (GSI), we verified the following decreasing order of sensitivity variation on the population dynamics for both insect species to model parameters:

$$
\text { IF }>R_{o} S f>A E>N M>\beta_{11}>\alpha_{22}>\beta_{12}>\beta_{22}>R_{o} H a>\alpha_{12}>C L>\beta_{21}>\alpha_{21}>\alpha_{11}
$$

The parameter most sensitive to variations in the population dynamics of the species S. frugiperda and H. armigera is the initial frequency of individuals, followed by the net reproduction of $S$. frugiperda, adult emergence, and natural mortality. On the other hand, the parameter with the lowest GSI is the survival rate of S. frugiperda in conditions of intraspecific competition at low densities (Figure 5). 


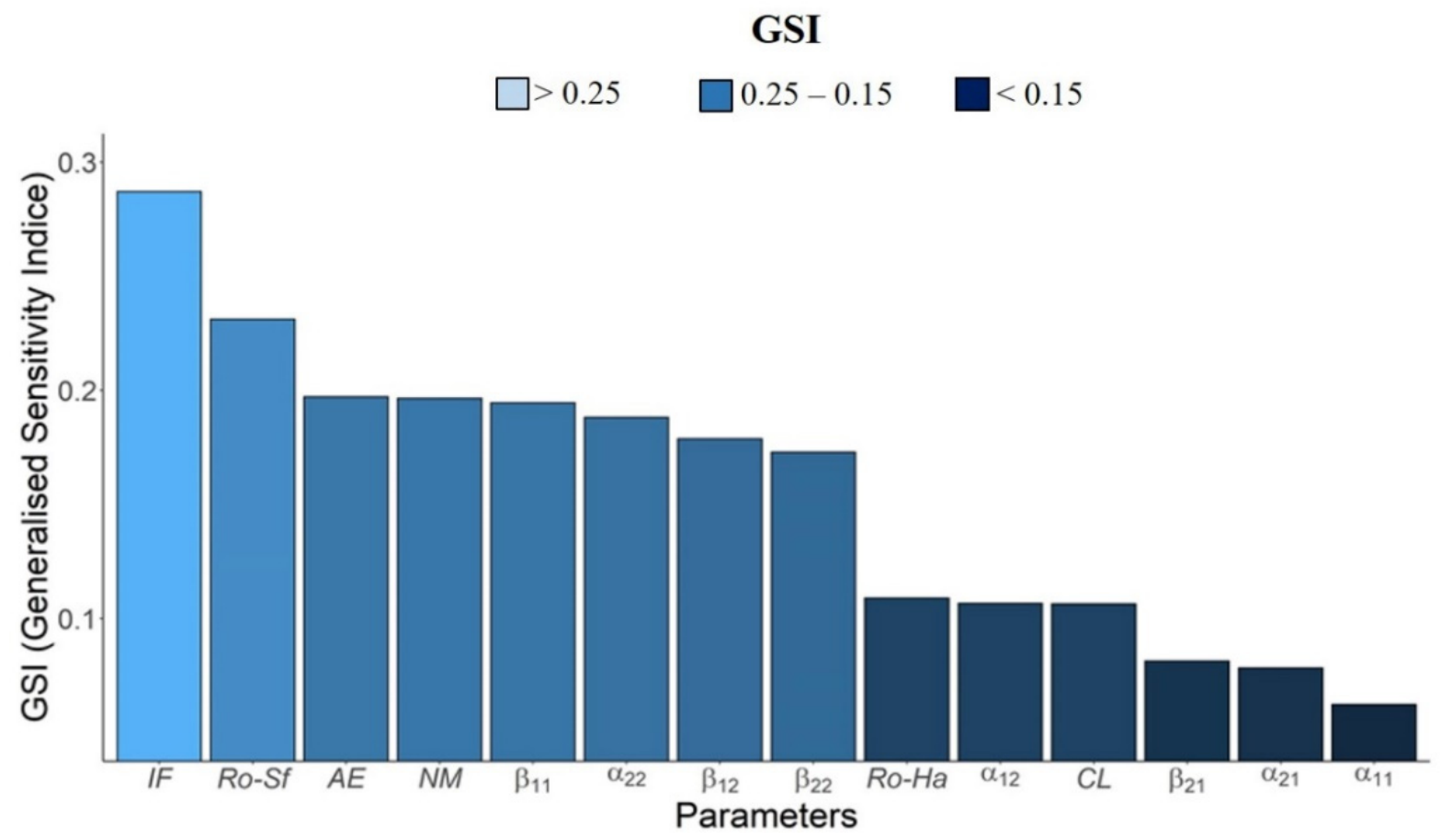

Figure 5. Generalized sensitivity index based on principal component analysis, for the following parameters: AE: Adult emergence. IF: Initial frequency. R0-Sf: Net reproduction rate of $S$. frugiperda. R0-Ha: Net reproductive rate of $H$. armigera. NM: Natural mortality. CL: Control level. $\alpha 11$ : Survival of S. frugiperda in intraspecific competition at low densities. $\alpha 12$ : Survival of S. frugiperda in intra- and interspecific competition at low densities. $\alpha 21$ : Survival of H. armigera in intra- and interspecific competition at low densities. $\alpha 22$ : Survival of $H$. armigera in intraspecific competition at low densities. $\beta 11$ : Survival of $S$. frugiperda in intraspecific competition at high densities. $\beta 12$ : Survival of $S$. frugiperda in intra- and interspecific competition at high densities. $\beta 21$ : Survival of $H$. armigera in intra- and interspecific competition at high densities. $\beta 22$ : Survival of H. armigera in intraspecific competition at high densities. (For a color version of this figure, the reader is referred to the web version of this article.).

\section{Discussion}

The interspecific competitive performance of $S$. frugiperda is higher in relation to $H$. armigera, except under conditions of high larval densities. Therefore, this result reveals that density can mediate shifts in ecological dominance between these two species, and that $H$. armigera is more responsive at high densities in the interspecific interaction with $S$. frugiperda. We try to explain the greater survival of $H$. armigera in relation to $S$. frugiperda in biological trials occurring at the highest density tested, providing four possible reasons.

The first reason may be supported by the intraspecific competition effect. This fact was verified independently of the density in isolated studies either with S. frugiperda or $H$. armigera larvae. In interspecific competition, the cannibalism could be more intense for $S$. frugiperda specimens in high densities in relation to $H$. armigera, which may have favored a greater survival rate of $H$. armigera when compared to that species. There is evidence that third instar $S$. frugiperda larvae increase intraspecific competition when food is scarce [38]. However, in other cases, the interaction of the diet with the opportunity to cannibalize is not important to $S$. frugiperda, indicating that the reduction in survival associated with the presence of members of the same species was uniform without relation to food availability [39]. We infer that the second reason may be related to the adverse effect of competition between species, or even that the attack and attempt to ingest the competitor may cause injury to the larvae, consequently affecting the development of the pest or possibly leading to death. In addition, food scarcity in this case influences the consumption of a greater number of dead bodies of larvae in plants, which may favor the dissemination of microorganisms, such as fungi, viruses, and bacteria that are important biological control agents for the regulation of these pest populations. 
The intra- and interspecific competition of larvae depends on the instar and, therefore, the stage of larval development [24,39-41]. Thus, we propose that the third reason could be due to the faster development of $H$. armigera larvae, promoting larger larvae in a short time and being more competitive in relation to S. frugiperda in the conditions of higher densities, because the consumption of its competitor can promote the intake of readily digestible and metabolizable food resources. The last reason could be linked to the intensification of the more aggressive behavior of H. armigera when the larvae are subjected to the highest densities and combined with S. frugiperda, because the proximity between them is considered one of the most important components to increase insect aggressiveness [42].

Computer simulations allowed us to infer that when the areas do not receive insecticide control to regulate the larval population, S. frugiperda is the dominant species; nevertheless, this scenario of not adopting insecticide control appears to be the most promising for the maintenance of the two lepidopteran species, and the closest to a sustainable program for resistance to $\mathrm{Bt}$ cotton. This above assumption is based on the fact that a smart program for managing insect resistance to plants that express $\mathrm{Bt}$, with structured refuges, must be designed in order to enable the production of a large number of susceptible adult insects with minimal economic costs and logistical impact for farmers [42].

The simulations demonstrated that when insecticide control is used for population regulation of these pests, the population dynamics of $H$. armigera is negatively affected, and its impact is even more intensified with the occurrence of $S$. frugiperda resistance to the insecticide used in refuge areas. For a refuge to be sufficiently effective to delay the evolution of insect resistance to Bt toxins, it is important to maximize the availability of susceptible adult insects [43], following the rule of production of at least 500 susceptible adults to a resistant adult [44]. Faced with the necessity for large-scale production of susceptible adults, our simulations highlight the importance of a sustainable management of populations of both S. frugiperda and H. armigera in refuge areas; in other words, with minimal use, and only when necessary, of insecticide.

The use of insecticides should be associated with proactive resistance management to insecticides used in refuge areas, especially for $S$. frugiperda. Our simulation results suggest that insecticide-free refuge areas favor the population expansion of $H$. armigera, and this is probably due to the influence of the density dependence, allowing H. armigera to be rewarded by a higher payoff due to the fact that this species has greater interspecific competitive capacity in relation to $S$. frugiperda under conditions of high density, and in addition, increasing the probability of exploiting patches not occupied by its competitor. The technologies of insecticide spray used currently rarely promote total mortality of the target insects [45], a factor incorporated in our computational model. Even when $H$. armigera larvae survive the insecticide spray, it was possible to infer that there is a low competitiveness of $H$. armigera by patches in the simulated refuge areas. This possibly adaptive density-dependent behavior strategy may be likely mediated by the reduction in cooperative interactions when there are few individuals [46].

In contrast to the lower population performance of $H$. armigera when the insecticide resistance of its competitor occurs, the greatest competitiveness of $H$. armigera at higher densities also allows us to reflect on the higher probability of population expansion of $H$. armigera in an agro-ecosystem with the occurrence of resistance of this species to insecticide and absence of resistance from its competitor, although with less population impacts for S. frugiperda. Such evidence motivates further studies involving the competition of these insects in a phenotypic context; that is, research involving the genotypes of $S$. frugiperda and $H$. armigera that are resistant, heterozygous, and susceptible to insecticides and/or Bt plants subjected to various conditions of selection pressure. Knowledge about the competitive potential of these insects in this phenotypic context will allow more accurate inferences to be made about the consequences of the competitive dynamics both for the evolution of the insects' resistance to the insecticides used in refuge areas and for Bt plants. The natural predation could also provide efficient resistance management with high refuge 
size because of strong density-dependent mortality [47]. Therefore, to meet the concept of sustainable management in refuge areas, experimental and modelling studies considering other control tactics available to manage lepidopteran species and other pest species, such as applied biological control [48], may be more pertinent.

In conclusion, the results from our biological experiments show a density depen-dence for the survival of $H$. armigera and S. frugiperda, when they are kept on cotton plants in isolation or in combination. S. frugiperda has a higher competitive performance compared to $H$. armigera, except in the condition of the highest density. Computer simulations allowed us to infer that the resistance of one of the species to the insecticides used in the areas of the refuge of Bt cotton negatively impacts the potential for population expansion of insects, and consequently, the abundance of these individuals, although S. frugiperda proves to be the species least sensitive to the insecticide resistance factor of its interspecific competitor. Therefore, according to the impact mentioned in the population structure of competing individuals and the probable reduction in the production of susceptible individuals, it is suggested that programs for managing the resistance of the studied species to Bt cotton may also adopt integrated and sustainable practices to avoid the resistance of species to the insecticides used in structured refuges. Thus, the adoption of such practices may, in addition, delay the evolution of insect resistance to Bt cotton with maximum production of Bt-susceptible individuals aimed in refuge areas of Bt cotton.

Author Contributions: J.B.M. and D.R.S.S. conceived the ideas and collected the data, J.B.M., D.R.S.S., P.E.D., C.P.F., E.P.d.M., W.A.C.G., J.K.d.S.P., F.d.S.R., C.O., A.I.d.A.P. and R.A.G. designed methodology, analyzed the data, and wrote the manuscript. P.E.D. and C.P.F. coordinated the projects. All authors contributed critically to the drafts and gave final approval for publication. All authors have read and agreed to the published version of the manuscript.

Funding: This study was funded by Fundação de Amparo à Pesquisa do Estado de São Paulo (FAPESP) (FAPESP process: 2018/20435-5, 2017/05953-7, 2015/20380-8) for granting the first author a Ph.D. and postdoctorate scholarships and for financing Project No. 2014/16609-7 (FAPESP). WACG, FSR, and CO are supported by a research fellowship from the Brazilian National Council for Scientific and Technological Development (CNPq).

Data Availability Statement: The data presented in this study are available in this article.

Conflicts of Interest: The authors declare that they have no competing interests.

\section{References}

1. Coulson, T.; Godfray, H.C.J. Single-species dynamics. In Theoretical Ecology: Principles and Applications; Chapter 3; May, R.M., McLean, A.R., Eds.; Oxford University Press: Oxford, UK, 2007; pp. 17-34.

2. Lang, J.M.; Benbow, M.E. Species interactions and competition. Nat. Educ. Knowl. 2013, 4, 8.

3. Carrara, F.; Giometto, A.; Seymour, M.; Rinaldo, A.; Altermatt, F. Inferring species interactions in ecological communities: A comparison of methods at different levels of complexity. Methods Ecol. Evol. 2015, 6, 895-906. [CrossRef]

4. Chu, C.; Mu, C.; Liu, J.; Liu, C.; Liu, C.; Boccaletti, S.; Shi, L.; Wang, Z. Aspiration-based coevolution of node weights promotes cooperation in the spatial prisoner's dilemma game. New J. Phys. 2019, 21, 063024. [CrossRef]

5. Flores, J.C. Game theory approach to sterile release populations and replicator dynamics: Niche fragmentation and resilience. Physical A 2020, 124212. [CrossRef]

6. Easley, D.; Kleinberg, J. “Games". Networks, Crowds, and Markets: Reasoning about a Highly Connected World; Cambridge University Press: Cambridge, UK, 2010; pp. 155-208.

7. Clements, K.C.; David, W.S. Testing models of non-kin cooperation: Mutualism and the prisoner's dilemma. Anim. Behav. 1995, 50, 527-535. [CrossRef]

8. Brown, J.S.; Staňková, K. Game theory as a conceptual framework for managing insect pests. Curr. Opin. Insect Sci. 2017, 21, 26-32. [CrossRef] [PubMed]

9. Bshary, R.; Oliveira, R.F. Cooperation in animals: Toward a game theory within the framework of social competence. Curr. Opin. Behav. Sci. 2015, 3, 31-37. [CrossRef]

10. Dourado, P.M.; Bacalhau, F.B.; Amado, D.; Carvalho, R.A.; Martinelli, S.; Head, G.P.; Omoto, C. High susceptibility to Cry1Ac and low resistance allele frequency reduce the risk of resistance of Helicoverpa armigera to Bt soybean in Brazil. PLoS ONE 2016, 11, e0161388. [CrossRef] [PubMed]

11. Tabashnik, B.E.; Gassmann, A.J.; Crowder, D.W.; Carrière, Y. Insect resistance to Bt crops: Evidence versus theory. Nat. Biotechnol. 2008, 26, 199-202. [CrossRef] [PubMed] 
12. Carrière, Y.; Brown, Z.S.; Downes, S.J.; Gujar, G.; Epstein, G.; Omoto, C.; Storer, N.P.; Mota-Sanchez, D.; Søgaard Jørgensen, P.; Carroll, S.P. Governing evolution: A socio-ecological comparison of resistance management for insecticidal transgenic Bt crops among four countries. AMBIO 2020, 49, 1-16. [CrossRef] [PubMed]

13. Head, G.; Dennehy, T. Insect resistance management for transgenic Bt cotton. In Cotton; Springer: Berlin/Heidelberg, Germany, 2010; pp. 113-125.

14. Andow, D.A.; Hutchison, W.D. Bt corn resistance management. In Now or Never: Serious New Plans to Save a Natural Pest Control; Union of Concerned Scientists, Ed.; Two Brattle Square: Cambridge, MA, USA, 1998; pp. 19-66.

15. Horikoshi, R.J.; Bernardi, D.; Bernardi, O.; Malaquias, J.B.; Okuma, D.M.; Miraldo, L.L.; Amaral, F.S.A.; Omoto, C. Effective dominance of resistance of Spodoptera frugiperda to Bt maize and cotton varieties: Implications for resistance management. Sci. Rep. 2016, 6, 34864. [CrossRef]

16. Farias, J.R.; Andow, D.A.; Horikoshi, R.J.; Sorgatto, R.J.; Fresia, P.; dos Santos, A.C.; Omoto, C. Field-evolved resistance to Cry1F maize by Spodoptera frugiperda (Lepidoptera: Noctuidae) in Brazil. Crop Prot. 2014, 64, 150-158. [CrossRef]

17. Omoto, C.; Bernardi, O.; Salmeron, E.; Sorgatto, R.J.; Dourado, P.M.; Crivellari, A.; Carvalho, R.A.; Wilsse, A.; Martinelli, S.; Head, G.P. Field-evolved resistance to Cry1Ab maize by Spodoptera frugiperda in Brazil. Pest Manag. Sci. 2016, 72, 1727-1736. [CrossRef] [PubMed]

18. Bernardi, D.; Salmeron, E.; Horikoshi, R.J.; Bernardi, O.; Dourado, P.M.; Martinelli, S.; Head, G.; Omoto, C. Cross-resistance between Cryproteins in fall armyworm (Spodoptera frugiperda) may affect the durability of current pyramided Bt maize hybrids in Brazil. PLOS ONE 2015, 10, e0140130. [CrossRef] [PubMed]

19. Leite, N.A.; Pereira, R.M.; Durigan, M.R.; Amado, D.; Fatoretto, J.; Medeiros, F.C.L.; Omoto, C. Susceptibility of Brazilian populations of Helicoverpa armigera and Helicoverpa zea (Lepidoptera: Noctuidae) to Vip3Aa20. J. Econ. Entomol. 2018, 111, 399-404. [CrossRef] [PubMed]

20. Malaquias, J.B.; Ramalho, F.S.; Omoto, C.; Godoy, W.A.C.; Silveira, R.F. Imidacloprid affects the functional response of predator Podisus nigrispinus (Dallas) (Heteroptera: Pentatomidae) to strains of Spodoptera frugiperda (JE Smith) on Bt cotton. Ecotoxicology 2014, 23, 192-200. [CrossRef] [PubMed]

21. Malaquias, J.B.; Omoto, C.; Ramalho, F.D.S.; Wesley, W.A.C.; Silveira, R.F. Bt cotton and the predator Podisus nigrispinus (Dallas) (Heteroptera: Pentatomidae) in the management of Spodoptera frugiperda (JE Smith) (Lepidoptera: Noctuidae) resistance to lambda-cyhalothrin. J. Pest Sci. 2015, 88, 57-63. [CrossRef]

22. Pereira, R.M.; Neto, D.A.; Amado, D.; Durigan, M.R.; Franciscatti, R.A.; Mocheti, M.; Omoto, C. Baseline susceptibility and frequency of resistance to diamide insecticides in Helicoverpa armigera (Lepidoptera: Noctuidae) populations in Brazil. Crop Prot. 2020, 137, 105266. [CrossRef]

23. Bolzan, A.; Padovez, F.E.; Nascimento, A.R.; Kaiser, I.S.; Lira, E.C.; Amaral, F.S.; Kanno, R.H.; Malaquias, J.B.; Omoto, C. Selection and characterization of the inheritance of resistance of Spodoptera frugiperda (Lepidoptera: Noctuidae) to chlorantraniliprole and cross-resistance to other diamide insecticides. Pest Manag. Sci. 2019, 75, 2682-2689. [CrossRef]

24. Bentivenha, J.P.F.; Baldin, E.L.L.; Montezano, D.G.; Hunt, T.E.; Paula-Moraes, S.V. Attack and defense movements involved in the interaction of Spodoptera frugiperda and Helicoverpa zea (Lepidoptera: Noctuidae). J. Pest Sci. 2016, 90, 433-445. [CrossRef]

25. Wise, D.H. Cannibalism, food limitation, intraspecific competition, and the regulation of spider populations. Annu. Rev. Entomol. 2006, 51, 441-465. [CrossRef]

26. Malaquias, J.B.; Caprio, M.A.; Godoy, W.A.C.; Omoto, C.; Ramalho, F.S.; Pachú, J.K.S. Experimental and theoretical landscape influences on Spodoptera frugiperda movement and resistance evolution in contaminated refuge areas of Bt cotton. J. Pest Sci. 2020, 93, 329-340. [CrossRef]

27. Turchin, P. Quantitative Analysis of Movement: Measuring and Modeling Population Redistribution in Animals and Plants; Sinauer Associates: Sunderland, MA, USA, 1998; 396p.

28. Ferreira, I.E.P.; Moral, R.A.; Ferreira, C.P.; Godoy, W.A.C. Modelling fungus dispersal scenarios using cellular automata. Ecol. Inform. 2013, 14, 53-58. [CrossRef]

29. Burtet, L.M.; Bernardi, O.; Melo, A.A.; Pes, M.P.; Strahl, T.T.; Guedes, J.V.C. Managing fall armyworm, Spodoptera frugiperda (Lepidoptera: Noctuidae), with Bt maize and insecticides in southern Brazil. Pest Manag. Sci. 2017, 73, 2569-2577. [CrossRef]

30. Kasten, P., Jr.; Precetti, A.A.C.M.; Parra, J.R.P. Dados biológicos comparativos de Spodoptera frugiperda (J.E. Smith) em duas dietas artificiais e substrato natural. Rev. Agric. 1797, 53, 68-78.

31. Embrapa-Empresa Brasileira de Pesquisa Agropecuária. Sistema Brasileiro de Classificação de Solos; Embrapa: Rio de Janeiro, Brazil, 2006; 306p.

32. Moral, R.A.; Hinde, J.; Demétrio, C.G.B. Half-normal plots and overdispersed models. In R: The hnp Package. J. Stat. Softw. 2017, 81, 1-23. [CrossRef]

33. Gomes, E.S.; Santos, V.; Ávila, C.J. Biology and fertility life table of Helicoverpa armigera (Lepidoptera: Noctuidae) in different hosts. Entomol. Sci. 2017, 20, 419-426. [CrossRef]

34. Barros, E.M.; Torres, J.B.; Bueno, A.F. Oviposição, desenvolvimento e reprodução de Spodoptera frugiperda (J.E. Smith) (Lepidoptera: Noctuidae) em diferentes hospedeiros de importância econômica. Neotrop. Entomol. 2010, 39, 996-1001. [CrossRef] [PubMed]

35. Varella, A.C.; Menezes-Netto, A.C.; Alonson, J.D.S.; Caixeta, D.F.; Peterson, R.K.D.; Fernandes, O.A. Mortality dynamics of Spodoptera frugiperda (Lepidoptera: Noctuidae) immatures in maize. PLoS ONE 2015. [CrossRef] [PubMed] 
36. Lamboni, M.; Makowski, D.; Lehuger, S.; Gabrielle, B.; Monod, H. Multivariate global sensitivity analysis for dynamic crop models. Field Crop. Res. 2009, 113, 312-320. [CrossRef]

37. Bidot, C.; Lamboni, M.; Monod, H. Multisensi: Multivariate Sensitivity Analysis. R Package Version 2.1-1. Available online: https: / /CRAN.R-project.org/package=multisensi (accessed on 1 July 2018).

38. Raffa, K.F. Effect of host plant on cannibalism rates by fall armyworm (Lepidoptera: Noctuidae) larvae. Environ. Entomol. 1987, 16, 672-675. [CrossRef]

39. Chapman, J.W.; Williams, T.; Escribano, A.; Caballero, P.; Cave, R.D.; Goulson, D. Fitness consequences of cannibalism in the fall armyworm. Spodoptera Frugiperda Behav. Ecol. 1999, 10, 298-303. [CrossRef]

40. Horner, T.A.; Dively, G.P.; Herbert, D.A. Development, survival and fitness performance of Helicoverpa zea (Lepidoptera: Noctuidae) in MON-Bt field corn. J. Econ. Entomol. 2003, 96, 914-924. [CrossRef] [PubMed]

41. Chilcutt, C.F. Cannibalism of Helicoverpa zea (Lepidoptera: Noctuidae) from Bacillus thuringiensis (Bt) transgenic corn versus non-Bt corn. J. Econ. Entomol. 2006, 99, 728-732. [CrossRef] [PubMed]

42. Dively, G.P.; Huang, F.; Oyediran, I.; Burd, T.; Morsello, S. Evaluation of gene fow in structured and seed blend refuge systems of non-Bt and Bt corn. J. Pest Sci. 2020, 93, 439-447. [CrossRef]

43. SAP (FIFRA Scientific Advisory Panel). Final Report of the FIFRA Scientific Advisory Panel Subpanel on Bacillus thuringiensis (Bt) Plant-Pesticides and Resistance Management. Docket No. OPPTS-00231; 1998; Volume 59, pp. 1-59. Available online: https://archive.epa.gov/scipoly/sap/meetings/web/pdf/finalfeb.pdf (accessed on 2 December 2020).

44. EPA (U.S. Environmental Protection Agency). Bt Plant-Pesticides Biopesticides Registration Action Document; EPA: Washington, DC, USA, 2000; 106p. Available online: http:/ / www.epa.gov/aphome/lawregs.htm (accessed on 2 December 2020).

45. Nansen, C.; Ridsdill-Smith, T.J. The performance of insecticides-A critical review. In Insecticides; Trdan, S., Ed.; InTech Europe: Rijeka, Croatia, 2013; pp. 195-232. [CrossRef]

46. Courchamp, F.; Clutton-Brock, T.; Grenfell, B. Inverse density dependence and the Allee effect. TREE 1999, 14, 405-410. [CrossRef]

47. Téllez-Rodríguez, P.; Raymond, B.; Morán-Bertot, I.; Rodríguez-Cabrera, L.; Wright, D.J.; Borroto, C.G.; Ayra-Pardo, C. Strong oviposition preference for Bt over non-Bt maize in Spodoptera frugiperda and its implications for the evolution of resistance. BMC Biol. 2014, 12, 48. [CrossRef] [PubMed]

48. Pachú, J.K.; Macedo, F.C.; da Silva, F.B.; Malaquias, J.B.; Ramalho, F.S.; Oliveira, R.F.; Godoy, W.A. Imidacloprid-mediated stress on non-Bt and Bt cotton, aphid and ladybug interaction: Approaches based on insect behaviour, fluorescence, dark respiration and plant electrophysiology. Chemosphere 2021, 263, 127561. 